\title{
A Review of Veterinary Antibiotic Pollution in the Agro-Environment of Pakistan: Alarm Bells Are Ringing
}

\author{
Muhammad Fahad Sardar ${ }^{1,3}$, Bilawal Abbasi ${ }^{2}$, Changxiong Zhu ${ }^{1}$, Muhammad Zia-ur-Rehman ${ }^{3}$, Ayesha Abdul \\ Qadir $^{3}$, Hamaad Raza Ahmad ${ }^{3}$, Sulman Siddique ${ }^{3}$, Ayesha Asghar ${ }^{4}$, Zongshou Wang ${ }^{5}$, Xue Liu ${ }^{1}$ and Hongna Li ${ }^{1 *}$ \\ ${ }^{1}$ Agricultural Clean Watershed Research Group, Institute of Environment and Sustainable Development in Agriculture, \\ Chinese Academy of Agricultural Sciences, Beijing 100081, P. R. China \\ ${ }^{2}$ Institute of Agricultural Resources and Regional Planning, Chinese Academy of Agricultural Sciences, Beijing 100081, P. R. China \\ ${ }^{3}$ Institute of Soil and Environmental Sciences, University of Agriculture, Faisalabad 38040, Pakistan \\ ${ }^{4}$ College of Agronomy, Northwest A\&F University, Yangling, Shaanxi 712100, P. R. China \\ ${ }^{5}$ Animal Husbandry and Veterinary Station, Nanping City, Fujian, 353000, P. R. China \\ *For correspondence: lihongna828@163.com \\ Received: 09 October 2020; Accepted: 05 January 2021; Published: 25 March 2021
}

\begin{abstract}
Veterinary antibiotics (VAs) are widely used in Pakistan for growth enhancement, production, and in the prevention and treatment of infectious diseases in the livestock and poultry industry. Their emergence into the agro-environment began during the resource utilization of farmyard and poultry manure. However, these bioactive organic pollutants are non-degradable in the natural environment and can be uptaken by plants, eventually ending up in the human food chain. Despite the danger these antibiotics pose, unfortunately, it is an issue that still remains underreported, especially in Pakistan. As such, this review critically summarizes the current consumption, exposure pathways, strategies for controlling dissemination, and serious environmental concerns associated with VAs. Additionally, the fate of antibiotics in the dry arid climate of Pakistan is thoroughly explained along with the lack of monitoring and strict legislation in developing countries. It is reported that antibiotic consumption negatively impacts raw manure, hence suggestions such as limiting the consumption of antibiotics from the source, proper disposal of farmyard manure with effective technologies, and remediation techniques are introduced. Finally, the authors highlight the importance of farmer's education and awareness campaigns in the pollution control of antibiotics, as the problem can only be properly addressed with the cooperation of government agencies, companies, and involved stakeholders. (C) 2021 Friends Science Publishers
\end{abstract}

Keywords: Farmyard manure; Antibiotics; Environmental pollution; Soil matrix; Strategies

\section{Introduction}

'Antibiotics' are termed as organic substances that are either extracted as byproducts of secondary metabolism of fungi, actinomycetes and bacteria or are prepared in pharmaceutical industries to counter the pathogenic microorganisms in living biota (Thiele-Brun and Peters 2007; Alduina 2020). Many antibiotics are widely used in feed as additives or injected in the blood (Zhu et al. 2017). In relation to that, veterinary antibiotics (VAs) have been utilized for the last seven decades, with their consumption increasing daily (Kuppusamy et al. 2018). To fulfil the requirements of meat and milk, the livestock industry is exponentially growing, and with the increase in the number of animals, the risks of animal infection and prevalence of pathogenic microorganisms increase as well (Selaledi et al. 2020). It is estimated that, in 2030, the usage rate of VAs will increase a hundredfold (Boeckel et al. 2015), with the concentration of these antibiotics consequently growing exponentially in agricultural soils, surface water, as well as in groundwater resources (Hu et al. 2010). The livestock industry's irrational consumption causes the release of 30 $90 \%$ of antibiotics as parent compounds or as secondary products. Such excretions must be monitored carefully, as these are the primary cause of antibiotic pollution (Benarab and Fangninou 2020). Chen et al. (2019) reported that nearly 70 kinds of antibiotics were detected in the agricultural environment. Current evidence suggests that a high concentration of antibiotics interferes with genes' functionality and imposes severe concerns on the genetic sequences. There are several entry channels of these antibiotics, with the most crucial route occurring through the food chain, and this is directly linked to manure utilization in agricultural lands (Coyne et al. 2020). The intake of these

To cite this paper: Sardar MF, B Abbasi, C Zhu, M Zia-ur-Rehman, AA Qadir, HR Ahmad, S Siddique, A Asghar, Z Wang, X Liu, H Li (2021). A review of veterinary antibiotic pollution in the agro-environment of Pakistan: alarm bells are ringing. Intl J Agric Biol 25:795-804 
antibiotics through the food chain imposes a potential threat to the human body's cell functioning and gut microbiota (Francino 2016). Furthermore, due to the misuse or overuse of antibiotics in Pakistan, a large number of the population develops antibiotic resistance (Saleem et al. 2020). In fact, this has become an issue plaguing many nations as, around the world, it has been reported that drug resistance-related diseases caused 700,000 deaths per annum (Alduina 2020).

Most studies only indicate the situation in developed countries, with reports considering developing countries, such as African and some Asian countries' ecological health, unavailable (Selaledi et al. 2020). Moreover, research publications collating the regulations and counterstrategies to cope with antibiotic pollution in the food chain of developing countries are very limited or unavailable, and no critical reviews have been conducted to compare and elaborate the impact of antibiotic pollution. Due to this, monitoring and controlling the prevalence of antibiotics, antibiotic-resistant genes, and corresponding microbial communities are necessary to protect the agro-ecosystem and consumers (Du and Liu 2012). Similarly, a thorough understanding of this newly emerging pollutant is required to predict and minimize its spread. Above all, the prime objectives of the current review are to discuss the following key points: (1) the use and abuse of antibiotics in the developing world with prime focus on Pakistan, (2) reservoirs of veterinary antibiotics, (3) the fate of antibiotics in the soil matrix, and (4) strategies to counter the effects of the emerging pollutant.

\section{Use and Abuse of Antibiotics in the World and Pakistan}

Globally, it is reported that 63,000-240,000 tons of antibiotics are consumed per annum, and by 2030, it is projected there will be a nearly $67 \%$ increase in the consumption of antibiotics (Tasho and Cho 2016). The annual global consumption of veterinary antibiotics in developed and underdeveloped countries is presented in Table 1. According to research, China leads in antibiotic consumption (Hu et al. 2010; Cycoń et al. 2019), with other developed countries, such as Germany and the USA, consuming tons of veterinary antibiotics as well (Du and Liu 2012).

Pakistan has a vast livestock and poultry market. It is estimated that the country has nearly 67.3 million large ruminants, 89.6 million small ruminants, and 1,230 million poultry (Rahman 2019). Pakistani farmers commonly transplant rice in standing water, and under these circumstances, there are significant chances of antibiotic leaching. Stoob et al. (2007) reports that wet conditions increase the leaching ability of VAs up to 15 times more than dry conditions. At the root cause of the issue are the indiscriminate and extensive use of antibiotics for the production of milk and meat along with the widespread availability of over-the-counter (OTC) medications that do not require a prescription. Furthermore, potent drugs against infectious diseases are misused by untrained veterinary doctors, uneducated local farmers, and fraudulent medical practitioners (Ali et al. 2020). However, due to the lack of surveillance and resources, there are no exact or estimated public reports about the consumption of VAs in Pakistan (Rahman 2019; Saleem et al. 2020).

\section{Reservoirs of Veterinary Antibiotics}

Land application of livestock waste is a common practice around the world, and it is the primary entry route of antibiotics in the agro-ecosystem (Fig. 1). In developed countries, the farmyard manure is treated before its application on agricultural soil. In Pakistan, the soils are impoverished in organic matter content $(1.29 \%)$. Due to farmers' miserable economic conditions and as a means to enhance agricultural soils' fertility status, $49 \%$ of farmyard manure is used as organic fertilizer and directly disposed of on land (Rahman 2019). Slaughterhouses are widespread in Pakistan, and nearly 8,000 tons of blood meal is produced annually to serve as a soil conditioner. Furthermore, due to the incomplete assimilation in an animal's gut, several kinds of antibiotics are also generated as liquid waste (Table 2). Therefore, several studies have been conducted worldwide to determine and control antibiotic dissemination in freshwater and wastewater effluents (Wei et al. 2011; Du and Liu 2012). Kumar et al. (2005) investigated the antibiotic concentration in manure slurry and reported up to $216 \mathrm{mg} \mathrm{L}^{-1}$ of antibiotics. In another study, it has also been reported that $50-60 \%$ of antibiotics are excreted as the parent compound or as an active metabolite in urine (Feinman and Matheson 1978). Fick et al. (2009) thoroughly investigated several antibiotics in wastewater effluents discharged by pharmaceutical companies and found a very high concentration of quinolones (14 mg L $\mathrm{L}^{-1}$ ). Hamscher et al. (2002) investigated the influence of liquid waste material and reported tetracycline concentrations of $172 \mathrm{mg} \mathrm{kg}^{-1}$ at 20 $30 \mathrm{~cm}$ depth of soil. This illegal discharge of hazardous compounds pollutes freshwater reservoirs and local communities. Afterwards, livestock wastewater gets mixed with sewage water, where it becomes a sink of antibiotics. Antibiotics in the dissolved or liquid form get transformed back to the parent compound; however, in the process, some antibiotics become inactive and are conjugated as acetylated metabolites (Christian et al. 2003; Chen et al. 2017). Due to the scarcity and high cost of freshwater, the farmer community generally disposes of or uses wastewater for irrigation purposes. Over time, the continuous dumping of solid livestock waste, unprocessed sewage water, and treated wastewater for irrigation becomes the primary reason for the buildup of heavy metals and VAs in the agricultural lands (Sardar et al. 2018). Owing to high mobility and leaching capacity, liquid waste is considered more dangerous than dry manure. 
Table 1: The annual global veterinary antibiotic consumption in developed and underdeveloped countries

\begin{tabular}{lll}
\hline Country & Consumption per annum (tons) & Reference(s) \\
\hline Australia & 932 & (Kim et al. 2010a, b) \\
Brazil & 2225 & (Kim et al. 2010a, b) \\
China & 210,000 & (Hu et al. 2010 ) \\
Denmark & 105 & (Du and Liu 2012) \\
France & 764 & (Du and Liu 2012) \\
Germany & 1900 & (Tasho and Cho 2016) \\
India & 1890 & (Hu et al. 2010$)$ \\
Iran & 1178 & (Hu et al. 2010) \\
Italy & 662 & (Hu et al. 2010) \\
Japan & 524 & (Hu et al. 2010) \\
Norway & 6 & (Kim et al. 2010a, b) \\
Russia & 915 & (Hu et al. 2010) \\
South Korea & 1278 & (Du and Liu 2012) \\
Spain & 343 & (Hu et al. 2010) \\
Sudan & 675 & (Hu et al. 2010) \\
Sweden & 16 & (Kim et al. 2010a, b) \\
Turkey & 1195 & (Hu et al. 2010) \\
UK & 308 & (Kim et al. 2010a, b) \\
USA & 14,600 & (Du and Liu 2012) \\
\hline
\end{tabular}

Table 2: The occurrence of veterinary antibiotics in different sources of livestock wastewater

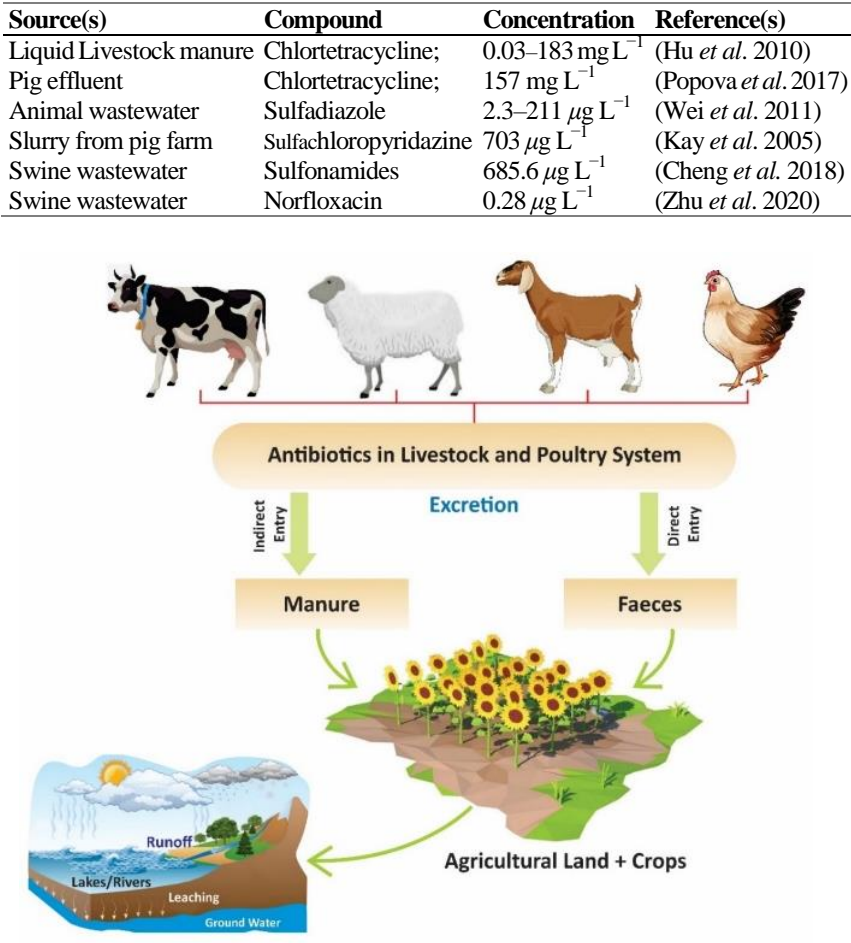

Fig. 1: Modes of entry of VAs into the agro-ecosystem through livestock and poultry

\section{Fate and Consequences of Veterinary Antibiotics in the Soils of Pakistan}

Once the antibiotics enter the soil matrix, they are prone to sorption/desorption or sequestration, transportation (leaching and surface runoff), transformation (biotic and abiotic), and uptake by the plants (Grossberger et al. 2014; Kuppusamy et al. 2018). The fate of antibiotics in an environment mainly depends on polarity, hydrophobicity, and the antibiotics' water-solubility properties (Christou $e t$ al. 2017) as well as on physicochemical properties of soil such as $\mathrm{pH}$, cation exchange capacity (CEC), mineral ions, soil or dissolved organic matter contents, soil structure, and texture (Vasudevan et al. 2009; Wu et al. 2013; Park and Huwe 2016).

\section{Mineralogy of Pakistani Soils}

Pakistan's climatic conditions are dry arid with long hot summers and short, mild winters. The soils lack organic matter and are alkaline with $\mathrm{pH}$ levels ranging between 8.35 and 9.05 (Ahmad et al. 2020). Soils of this region mainly possess kaolinite, mica, vermiculite, and smectite type minerals. These minerals determine specific chemical characteristics of soils. For example, kaolinite-dominated soils have low CEC, whereas soil with a high amount of vermiculite retains high CEC. These factors are known to influence the dissemination of organic pollutants, such as antibiotics.

\section{Sorption/Desorption/Sequestration}

Antibiotics entering the soil with manure application remain mostly on the soil surface (Aust et al. 2009; Ostermann et al. 2013). The adsorption and desorption mechanisms are observed with non-polar and neutral antibiotics, whereas the polar and ionizable antibiotics remain in the soil solution (Thiele-Bruhn et al. 2004; Wegst-Uhrich et al. 2014). For instance, sulfathiazole and sulfamethazine (which are neutral/cationic nature in a soil solution) express their high sorption affinity with ionic soil surfaces at $\mathrm{pH}$ levels lower than 7.5 (Kurwadkar et al. 2011). Divalent cations in soil form complexes with tetracycline (Hamscher et al. 2002), hence, the type of cations in the soil also controls the adsorption of Vas (Fig. 2). The sequestration of VAs into micro or nanopores with aging also decreases their bioavailability and bio-accessibility, albeit a certain amount remaining in the soil system (Forster et al. 2009). For the time being, the acute toxicity of VAs is reduced due to this process; however, sequestration is a reversible process that later releases sequester VAs back into its bioavailable form (Zarfl et al. 2009). Permanent unavailability of VAs occurred with the physical diffusion of these antibiotics into soil organic matter, oxides, or clay interlayer nanopores and with the formation of enzymatically catalyzed covalent bonds (Gulkowska et al. 2013; Jechalke et al. 2014).

\section{Runoff/Leaching}

Transportation of antibiotics occurs either via surface water 
bodies or groundwater aquifers when they dissolve in the soil solution (Alder et al. 2001; Davis et al. 2006). Soil pH plays a prominent role in the runoff and leaching of antibiotics. The charge of dissociating functional groups changes, with the $\mathrm{pH}$ of the soil fluctuating and consequently influencing the transport behavior of VAs. Since the $\mathrm{pH}$ of Pakistani soil is mostly alkaline or above 7.5, leaching of the negatively charged antibiotics (e.g., sulfonamides) can increase (Kurwadkar et al. 2011; Strauss et al. 2011). In another research, weakly acidic antibiotics (e.g., naproxen) were found to be present in the soil solution, and this kind of antibiotic exhibited high movement due to the dissociated carboxylic functional group (Schaffer et al. 2012).

Low soil organic matter contents $(<1 \%)$ might enhance the mobility of antibiotics in Pakistani soil. It is reported that as soil organic matter increases, the sorption of antibiotics increases while the mobility decreases (Borgman and Chefetz 2013). On the other hand, an increase in dissolved organic matter content enhances VAs' mobility (Kulshrestha et al. 2004). It is reported that well-plowed soil amended with manure highly prevents the transport of VAs to groundwater, because small macropores play a key role in controlling the movement of VAs in soil (Kay et al. 2005). Antibiotics are easily transported from one part of the manure or wastewater applied field to the other or nearby water bodies due to flood irrigation, which is the wellpracticed irrigation method in Pakistan. The transport of antibiotics also occurs with shared farm machinery and wind erosion (Dalkmann et al. 2012).

\section{Transformations}

The primary remediation mechanisms of antibiotics involve adsorption, biodegradation, hydrolysis, and volatilization (Gurmessa et al. 2020). Veterinary antibiotics like $\beta$-lactams, macrolides, tetracyclines, fluoroquinolones, and trimethoprim mainly follow the adsorption mechanism, whereas sulfonamides type antibiotics are generally removed along with the biodegradation mechanism (Li and Zhang 2010; Jia et al. 2018; Sui et al. 2018; Zhang and Li 2018).

\section{Impact on Microbial Diversity}

The microbial community structure holds great potential to sustain and improve soil productivity and partially cope with food security and soil degradation (National Academies of Sciences, Engineers and Medicine 2018). Singh and Trivedi (2017) stated that microbes are responsible for soil and crop productivity's essential functions. Indeed, bacteria play a crucial role in the supply of macro and micronutrients through host-specific interactions (Lehto and Zwiazek 2010). However, microbial activity and efficiency directly depend on the environmental conditions; soil microflora, bacterial communities and other microorganisms face severe threats due to the accumulation of bioactive hazardous substances (e.g., antibiotics) in soil (Cycoń et al. 2019). Prolonged exposure to these antibiotics leads to the development of resistance in the soil's microbial community, which eventually affects the resident's health. The toxicity due to these antibiotics can also impart changes in the normal functioning of bacterial and microbial populations. Ultimately, these antibiotics result in the death of essential microbes that provide nutrients, imbalance in the community structure, and increased occurrence of several types of antibiotic-resistant genes (Knapp et al. 2011). In addition to soil microbial communities, farmyard manure laden with antibiotics also significantly impacts microbial communities in crop plants (Cycoń et al. 2019). Animal manure is a primary source of ARBs in the soil matrix, and most of the species are reported as human pathogens (Yang et al. 2013). In relation to that, the application of animal manure disturbs the proportion of endophytic bacterial populations in crops (Zhang et al. 2013). Similar results were reported in another study that cattle and poultry manure could enhance the abundance of antibiotic-resistant genes in root endophytes (Zhang et al. 2019).

In the context of environmental conditions, soil properties are of utmost importance. Along with other physicochemical factors, soil texture is relatively vital, due to the role it plays in the survival of fecal bacteria in agricultural soils (Franz et al. 2014). Antibiotics have a varied correlation with microbial structure across several textural classes, and it is imperative to understand the influence of antibiotic consumption and excretion along with its correlation to the indigenous microbial community.

\section{Entry of Veterinary Antibiotics in the Food Chain}

Irrational and repetitive disposal of farmyard manure laden with antibiotics may ultimately build up concentration high enough to enter the terrestrial environment as an active hazardous substance (Bassil et al. 2013). Because this is the first entry channel of antibiotics in the animal and human food chain, the possibility of bio-accumulation and biomagnification of VAs at this stage cannot be ignored (Fig. 3). Previous studies reveal that oxytetracycline, chlortetracycline, penicillin, and sulfamethazine have moderate bio-accumulation potential (Thiele-Brun and Peters 2007), while tylosin, monensin, bacitracin, and virginiamycin have low bio-accumulation potential (Luby et al. 2016). Different plant organs and tissues have different responses to the toxic effect of these antibiotics, with their response depending on the concentration of antibiotics and exposure time. Hillis et al. (2011) conducted a detailed investigation and reported that lower antibiotic concentration enhances nodes and internodes' growth, while cotyledons and roots showed a negative growth response.

Chitescu et al. (2013) reported that root crops are more prone to antibiotic accumulation, as they directly contact soil and farmyard manure. The uncontrolled raw manure 


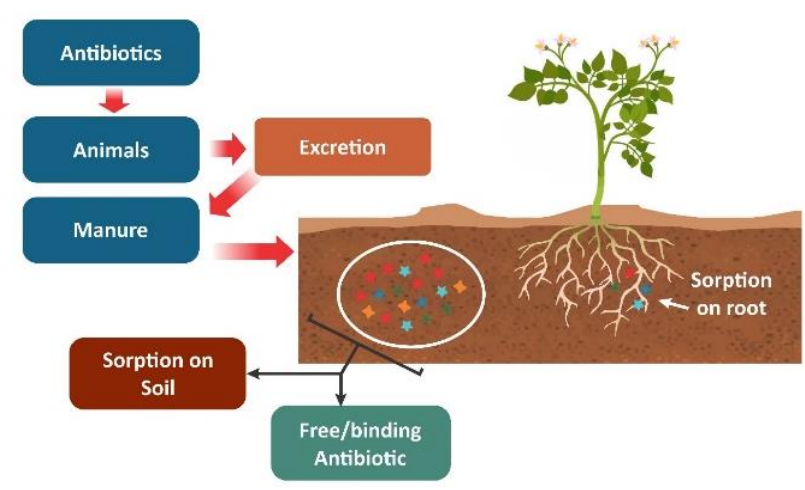

Fig. 2: Sorption behavior of veterinary antibiotics in the soil matrix

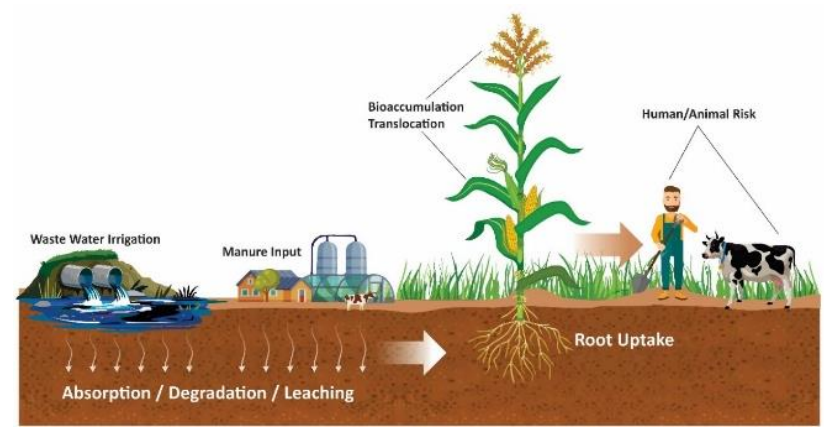

Fig. 3: Possible pathways of veterinary antibiotics in the soil and food chain

application threatens the safe production of staple foods such as potato, millet, wheat, and corn. Recent studies have also revealed the possible molecular level impact of antibiotics on plants' metabolic functioning (Zhang et al. 2020). Minden et al. (2017) investigated the woody plants' remediation potential and highlighted that such plants could restore the antibiotic polluted soils.

\section{Strategies to Counter Veterinary Antibiotic Pollution}

The potential outcomes of antibiotic and corresponding resistant gene pollution cannot be ignored. Regulations and strategies must be adopted to reduce the deterioration of the agro-ecosystem. Targeted awareness companies can reduce this emerging pollutant entry in soil, plants, and the food chain. Nonetheless, it is important to note that these strategies can only be adopted if governments provide financial support to poor and uneducated farmers, as such financial benefits will provide them with the necessary resources and encourage them to adopt farm level strategies and cooperate with the legal authorities.

\section{Proper Disposal of Farmyard Manure}

The proper disposal and recycling of farmyard manure is also an important area to be determined, and it should be cost-effective and easy to adopt by farmers and other stakeholders. At the commercial scale, millions of tons of livestock waste are generated annually, and its disposal would require enormous resources, necessitating the implementation of policy plans by governments and local administrations on the utilization and safe disposal of this organic waste. Numerous reports have been published about the aerobic techniques to counter antibiotic pollution, and these techniques are claimed to be highly (> 99\%) efficient (Ho et al. 2013; Song et al. 2020).

\section{Physiochemical Strategies}

There are several conventional and advanced techniques to control antibiotic pollution and corresponding resistant determinants in the agro-environment.

To deploy the advanced treatments, we recently conducted a series of experiments using ultraviolet (UV) radiation against antibiotic-resistant bacteria in biologically treated wastewater. The wastewater samples used in our previous study were collected from a cyclic activated sludge system. As a disinfectant of treated wastewater, UV radiation substantially impacted phenotypes and genotypes of antibiotic-resistant bacteria. We found that the proportion of Gram-positive and Gram-negative bacteria varied with UV fluence (Zhang et al. 2019).

Strong oxidizing agents are one of the newly adopted strategies, since the ozone can oxidize several classes of organic materials (Nakonechny et al. 2007). A recent study by Chu et al. (2020) showed favorable results on cephalosporin's remediation ( $\beta$-lactam class). In this study, ozonation, irradiation, and heat treatment were used for degradation, and ozone showed $79.9 \%$ removal efficiency, while $85.5 \%$ by radiation; 71.9 and $87.3 \%$ by heat treatment at 60 and $90^{\circ} \mathrm{C}$ for $4 \mathrm{~h}$, respectively. However, a major disadvantage of ozonation is its high cost, need for equipment, and gross energy consumption.

Fenton's reagent is a demanding technique among the various oxidation processes due to its strong oxidizing efficiency (Gan et al. 2009). Moreover, Photo-Fenton and Fenton procedures have a higher antibiotic removal percentage than the traditional Fenton procedure. Rozas et al. (2010) achieved complete removal of ampicillin at 3 and $10 \mathrm{~min}$ for photo-Fenton and Fenton, respectively, by adjusting different variables like $\mathrm{Fe}^{2+}$ concentration (87 $\mathrm{mol} / \mathrm{L}), \mathrm{H}_{2} \mathrm{O}_{2}(400 \mathrm{~mol} / \mathrm{L})$ and $\mathrm{pH}$ (3.5).

The photolysis involves direct and indirect use of light to decompose organic effluent into intermediates, which in turn can be hydrolyzed into non-toxic end products (Lofrano et al. 2017). Despite photolysis being more economical than other methods, it can only be useful for freshwater containing light-sensitive compounds. Apart from that, the process' efficiency is strongly dependent on the nature, $\mathrm{pH}$, and fate of antibiotics (Shi et al. 2020). 
The Electrochemical (EC) disinfectant technique is comparatively easier to adopt and apply, and it is known to work without the requirements of chemicals and complicated procedures. Therefore, in our previous work, we conducted a laboratory-scale EC experiment to explore the wastewater's antibiotic-resistant status and investigated various antibiotic drugs: tetracycline, sulfadiazine, penicillin, erythromycin, vancomycin, gentamicin and chloramphenicol ofloxacin and ciprofloxacin. It was found that EC disinfection decreases the relative abundance of antibiotic-resistant genes, thus, proving to be a promising technique to control antibiotic dissemination (Li et al. 2019, 2020).

\section{Adsorption}

Adsorption is an easy method for removing organic compounds, but it has not been widely proven to eliminate antibiotics (Yu et al. 2016). Based on the forces involved, adsorption can be categorized as physical and chemical. The most common adsorbents used to remove antibiotics are clay mineral, biochar, carbon nanotubes, bentonite and activated carbon. Méndez-Díaz et al. (2010) achieved approximately $90 \%$ removal efficiency of sulfonamides and imidazoles by using activated charcoal as an adsorbent. Similarly, by batch and continuous techniques, trimethoprim was maximum (Kim et al. 2010a, b). Kim et al. (2014) used single and multi-walled nanotubes to absorb sulfamethoxazole and lincomycin and found that singlewalled nanotubes were more efficient at adsorbing pollutants. Hence, due to its low cost, high yield, and lack of hazardous byproducts, it is well adapted for the separation and disposal of antibiotics. In contrast to the specific methods described above, adsorption can also be applied to water that contains a high proportion of antibiotics or organic matter, with the disadvantage being that these are only removed and concentrated.

Several membrane processes are commonly used in various applications, with this method permitting separation and concentration by transferring it to the membrane. Reverse osmosis, ion exchange, nanofiltration, ultrafiltration, and combined processes have been used to achieve the goal of separating antibiotics through membrane processes. Combined and hybrid methods are the most efficient for application at the industrial level. Therefore, integrated processes were used. In the case of degradation in which most microorganisms are sensitive to certain chemicals or mechanisms, combined methods must be used. Similarly, advanced oxidation processes must also be used as a pre-treatment process in which organics or contaminants are pre-treated to convert them into less toxic substances that can be easily broken down and disposed of (Homem and Santos 2011). A combination of Fenton and reverse osmosis was used to remove amoxicillin (Elmolla and Chaudhuri 2010). Although this method is an effective and potential technique, it is not used to remove antibiotics due to its complexity.

\section{Biological Pathways of Antibiotic Degradation}

The scientific community has adopted biodegradation due to its low cost, ease of operation, and absence of toxic byproducts generated. The biological degradation of antibiotics can be achieved with plants, biocatalysts, and microorganisms, each of which has its own advantages and disadvantages in the effective removal of antibiotics. The outcome of these processes depends on factors such as temperature, $\mathrm{pH}$, and structure.

\section{Composting}

Composting includes a series of manure management activities that use microbial processes to aerobically decompose organic matter, stabilize waste, and reduce pathogens and odors. In some cases, organic materials such as dried leaves and sawdust are mixed with manure pile to balance the carbon and nitrogen ratio and improve aeration and nutritional status. The compost can also be turned to increase the utilization rate of oxygen in a pile (USDA 2009). During composting, the temperature of the manure pile is increased by microbial processes. However, manure incubated at a lower temperature shows less treatment efficiency. Hence, antibiotic treatment is attributed to temperature-dependent abiotic processes such as adsorption and degradation. Kim et al. (2012) noted that compounds produced during composting by microbial processes formed complexes with antibiotics (sulfamethazine, chlortetracycline, and tylosin). In several studies, the lower removal efficiency was reported for ciprofloxacin (Selvam et al. 2012), sulfamethazine, monensin (Dolliver et al. 2008) chlortetracycline (Bao et al. 2009).

The collective effect of different antibiotics is primarily responsible for the enrichment of antibiotic resistance in conventional composting (Song et al. 2020). Our recent research article has thoroughly investigated the role of conventional composting in the degradation of commonly used veterinary antibiotics (e.g., lincomycin, chlorotetracycline, sulfamethoxazole, and ciprofloxacin). To ensure the comparability of results, $50 \mathrm{mg} / \mathrm{kg}$ was selected as a uniform concentration of each antibiotic. We found that ciprofloxacin had a more significant influence on the physicochemical and biological characters of compost. The antibiotics were gradually degraded in all the treatments; even so, the degradation rate was lower in a treatment comprising a mixture of antibiotics.

However, conventional composting cannot efficiently control antibiotics, antibiotic-resistant genes, nor antibioticresistant bacteria. Several classes of antibiotics (e.g., tetracyclines and sulfonamides) remain high in the final compost. Indeed, the impact of composting is still unclear, requiring further comprehensive investigation. To explore the composting process and its stage-specific effect on antibiotics, we conducted temperature-programmed aerobic composting and found that the controlled thermophilic 


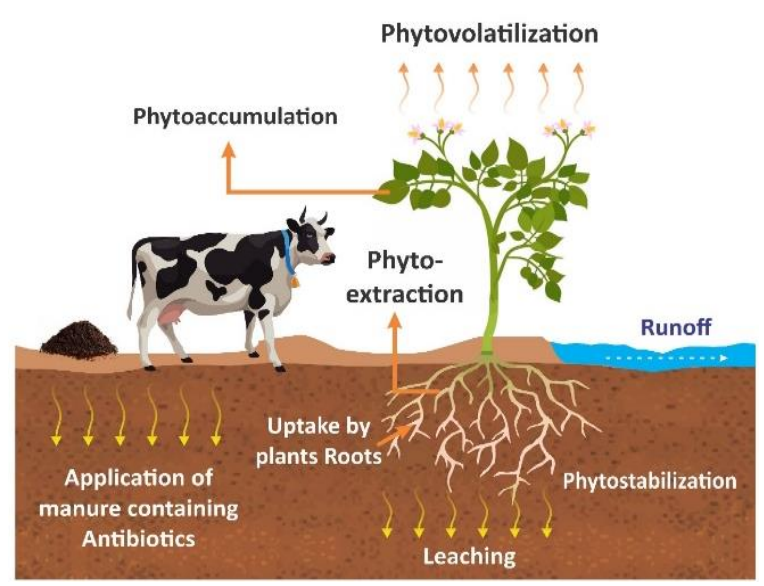

Fig. 4: Various approaches for phytoremediation of VAs

phase increased the degradation of sulfamethoxazole, while the abundance of ARGs was reduced. Temperature reduction enhanced ARGs, which may be due to the rebounding of potential carriers. Furthermore, controlled composting was still insufficient to counter these newly emerging pollutants, and optimization of operational conditions was suggested (Sardar et al. 2021).

\section{Anaerobic Digestion}

Anaerobic digestion is a two-step process in which part of the organic manure is first hydrolyzed and then changed into volatile fatty acids by acid-forming bacteria (Macias-Corral et al. 2008). The methanogenic bacteria then convert volatile fatty acids into methane (Macias-Corral et al. 2008). Several studies have been conducted for antibiotic removal by anaerobic digestion from farmyard manure (Arikan et al. 2006; Arikan 2008; Mitchell et al. 2013) and swine manure (Stone et al. 2009). Sara et al. (2013) reported that antibiotic biodegradation efficiency increased by thermal pretreatment before anaerobic digestion.

\section{Phytoremediation of Veterinary Antibiotics}

Plants are the natural sink of environmental contaminates and hazardous substances (Tasho and Cho 2016) and so, VAs that are laden in the soil from livestock waste are taken up by plants (Bassil et al. 2013). This continuous exposure leads to bioaccumulation and eventually phytotoxicity to the crops. A schematic mechanism behind phytoremediation is presented in Fig. 4. The accumulation of these antibiotics is dependent on the concentration and exposure time (Pan and Chu 2017). Generally, plants grown on humus-deficient soils have a high affinity to accumulate antibiotics (Chen et al. 2019), with several plant species tested and shown to bioaccumulate the antibiotics (Bassil et al. 2013; Chitescu et al. 2013; Minden et al. 2017). Bao et al. (2016) investigated the ability of green pepper, potato, sweet potato, Chinese cabbage, lettuce, carrot, bitter melon, and white gourd to accumulate different classes of sulfonamide drugs. Phytoremediation techniques should be adopted to make the soil safe and reliable, but to adopt such remedial strategies, a compromise may be needed for the resources and economic constraints of farmers. Additionally, there would be a financial burden on stakeholders. Therefore, such programs should be adopted with the support of the government and other administrative agencies.

\section{Regulated Consumption of Antibiotics}

The problem with the consumption of VAs in the livestock industry and the disposal of farmyard manure in agricultural fields is well known, but there is a lack of monitoring and legislation implementation. Large scale consumption of VAs for growth enhancement, milk, and meat production is strictly banned in South Korea and China. However, developed countries such as China, USA, and European countries consume these antibiotics, with the production of such VAs still prevalent (Wu et al. 2019).

Many countries have improved legislation and banned unnecessary licensing. This could be an excellent strategy to controlling the dissemination of VAs, but dealing with the removal of licensed antibiotics and its popularity among the farmer communities remains a challenge.

Another possible way is to focus on infectious diseases and specify a particular antibiotic's type and dosage. Administrative and medical authorities should carefully examine the animal and prescribe antibiotics only when absolutely necessary (Tasho and Cho 2016; Xue et al. 2019). Farmers and medical workers should record prescribed medicine, and administrative agents should regularly monitor their dosage and record (Ali et al. 2020).

\section{Awareness Programs}

Developing and underdeveloped countries have a vast number of uneducated and poor farmers. Awareness on the proper disposal of waste, environmental pollution, safe production, and effects on human health is limited (Buelow et al. 2020; He et al. 2020). To efficiently control environmental pollution issues, especially antibiotic pollution, all solutions must begin with education. Both the government and private sector should be called upon to develop awareness campaigns to educate stakeholders such as influential scientists, young researchers, and educated farmers on the use and abuse of antibiotics and train them to properly treat the livestock waste on their lands.

\section{Concluding Remarks}

Although the fertility status of soil is dependent on the application of farmyard manure, it is evident from the current review that antibiotic consumption can negatively impact raw manure. Thus, this source of antibiotic pollution must be addressed. A useful strategy would be the 
implementation of a ban on the misuse of drugs. As proposed in this review, the scientific community and government agencies should develop policies and legislation to counter and restrict this emerging issue. Awareness campaigns must be launched at a large scale to ensure the human and animal food chain's safety and to control environmental pollution. All these are crucial to solving the underreported issue in developing countries like Pakistan.

\section{Acknowledgements}

This work was jointly supported by the Young Elite Scientist Sponsorship Program of BAST (Beijing Association for Science and Technology) (2019-2021), Beijing Municipal Natural Science Foundation (6192029, 8182059), and Basic Research Funds for Central Research Institutes of China (BSRF201903).

\section{Author Contributions}

Conceptualization, MFS and HL. Graphics: BA, SS and AA. Investigation: MFS, AAQ, MZR, ZW and HRA. Writing, original draft preparation: MFS and HL. Review and editing: MFS, CZ and HL. Funding acquisition: CZ, XL and HL. All authors have read and agreed to the published version of the manuscript.

\section{Conflict of Interest}

There is no conflict of interest among the authors

\section{Ethics Approval}

Not applicable

\section{References}

Ahmad HR, K Mehmood, MF Sardar, MA Maqsood, MZU Rehman, C $\mathrm{Zhu}, \mathrm{H} \mathrm{Li} \mathrm{(2020).} \mathrm{Integrated} \mathrm{risk} \mathrm{assessment} \mathrm{of} \mathrm{potentially} \mathrm{toxic}$ elements and particle pollution in urban road dust of megacity of Pakistan. Hum Ecol Risk Assess 26:1810-1831

Alder AC, CS McArdell, EM Golet, S Ibric, E Molnar, NS Nipales, W Giger (2001). Occurrence and fate of fluoroquinolone, macrolide, and sulfonamide antibiotics during wastewater treatment and in ambient waters in Switzerland. In: Pharmaceuticals and Care Products in the Environment, Vol. 791, pp:56-69. American Chemical Society, Washington DC, USA

Alduina R (2020). Antibiotics and environment. Antibiotics 9:202-204

Ali M, BH Abbasi, N Ahmad, H Fazal, J Khan, SS Ali (2020). Over-thecounter medicines in Pakistan: Misuse and overuse. Lancet 395:116116

Arikan OA (2008). Degradation and metabolization of chlortetracycline during the anaerobic digestion of manure from medicated calves. $J$ Haz Mater 158:485-490

Arikan OA, LJ Sikora, W Mulbry, SU Khan, C Rice, GD Foster (2006). The fate and effect of oxytetracycline during the anaerobic digestion of manure from therapeutically treated calves. Process Biochem $41: 1637-1643$

Aust MO, S Thiele-Bruhn, J Seeger, F Godlinski, R Meissner, P Leinweber, (2009). Sulfonamides leach from sandy loam soils under common agricultural practice. Water Air Soil Pollut 211:143-156
Bao L, L Qu, K Ma, L Lin (2016). Effects of road dust on the growth characteristics of Sophora japonica L. seedlings. J Environ Sci 46:147-155

Bao Y, Q Zhou, L Guan, Y Wang (2009). Depletion of chlortetracycline during composting of aged and spiked manures. Waste Manage 29:1416-1423

Bassil RJ, II Bashour, FT Sleiman, YA Abou-Jawdeh (2013). Antibiotic uptake by plants from manure-amended soils. $J$ Environ Sci Health 48:570-574

Benarab N, FF Fangninou (2020). The issues of Antibiotics: Cephalexin Antibiotic as emerging environment contaminant. Intl J Sci Res Publ 10:9843-9855

Boeckel TPV, C Brower, M Gilbert, BT Grenfell, SA Levin, TP Robinson, A Teillant, R Laxminarayan (2015). Global trends in antimicrobial use in food animals. Proc Natl Acad Sci USA 112:5649-5654

Borgman O, B Chefetz (2013). Combined effects of biosolids application and irrigation with reclaimed wastewater on transport of pharmaceutical compounds in arable soils. Water Res 47:3431-3443

Buelow E, A Rico, M Gaschet, J Lourenço, SP Kennedy, L Wiest, MC Ploy, C Dagot (2020). Hospital discharges in urban sanitation systems: Long-term monitoring of wastewater resistome and microbiota in relationship to their eco-exposome. Water Res X 7; Article 100045

Chen KL, LC Liu, WR Chen (2017). Adsorption of sulfamethoxazole and sulfapyridine antibiotics in high organic content soils. Environ Pollut 231:1163-1171

Chen X, Y Zhao, C Zeng, Y Li, L Zhu, J Wu, J Chen, Z Wei (2019). Assessment contributions of physicochemical properties and bacterial community to mitigate the bioavailability of heavy metals during composting based on structural equation models. Bioresour Technol 289:121657

Cheng DL, HH Ngo, WS Guo, YW Liu, JL Zhou, SW Chang, DD Nguyen, XT Bui, XB Zhang (2018). Bioprocessing for elimination antibiotics and hormones from swine wastewater. Sci Tot Environ 621:1664-1682

Chitescu CL, AI Nicolau, AAM Stolker (2013). Uptake of oxytetracycline, sulfamethoxazole and ketoconazole from fertilised soils by plants. Food Addit Contam Part A 30:1138-1146

Christian T, RJ Schneider, HA Färber, D Skutlarek, MT Meyer, HE Goldbach (2003). Determination of antibiotic residues in manure, soil, and surface waters. Acta Hydrochim Hydrobiol 31:36-44

Christou A, A Agüera, JM Bayona, E Cytryn, V Fotopoulos, D Lambropoulou, CM Manaia, C Michael, M Revitt, P Schröder, D Fatta-Kassinos (2017). The potential implications of reclaimed wastewater reuse for irrigation on the agricultural environment: The knowns and unknowns of the fate of antibiotics and antibiotic resistant bacteria and resistance genes - A review. Water Res 123:448-467

Chu L, D Chen, J Wang, Z Yang, Q Yang, Y Shen (2020). Degradation of antibiotics and inactivation of antibiotic resistance genes (ARGs) in Cephalosporin $\mathrm{C}$ fermentation residues using ionizing radiation, ozonation and thermal treatment. J Haz Mater 382:121058

Coyne L, I Patrick, R Arief, C Benigno, W Kalpravidh, J McGrane, L Schoonman, AH Sukarno, J Rushton (2020). The costs, benefits and human behaviors for antimicrobial use in small commercial broiler chicken systems in Indonesia. Antibiotics 9; Article 154

Cycon M, A Mrozik, Z Piotrowska-Seget (2019). Antibiotics in the soil environment-degradation and their impact on microbial activity and diversity. Front Microbiol 10; Article 338

Dalkmann P, M Broszat, C Siebe, E Willaschek, T Sakinc, J Huebner, W Amelung, E Grohmann, J Siemens (2012). Accumulation of pharmaceuticals, enterococcus, and resistance genes in soils irrigated with wastewater for zero to 100 years in Central Mexico. PLoS One 7; Article e45397

Davis JG, CC Truman, SC Kim, JC Ascough, K Carlson (2006). Antibiotic transport via runoff and soil loss. J Environ Qual 35:2250-2260

Dolliver H, S Gupta, S Noll (2008). Antibiotic degradation during manure composting. J Environ Qual 37:1245-1253

Du L, W Liu (2012). Occurrence, fate, and ecotoxicity of antibiotics in agro-ecosystems. A review. Agron Sustain Dev 32:309-327 
Elmolla ES, M Chaudhuri (2010). Effect of photo-fenton operating conditions on the performance of Photo-Fenton-SBR process for recalcitrant wastewater treatment. $J$ Appl Sci 10:3236-3242

Feinman SE, JC Matheson (1978). Draft Environmental Impact Statement Subtherapeutic Antibacterial Agents in Animal Feeds. Bureau of Veterinary Medicine, Food and Drug Administration, Rockville, Maryland, USA

Fick J, H Söderström, RH Lindberg, C Phan, M Tysklind, DGJ Larsson (2009). Contamination of surface, ground, and drinking water from pharmaceutical production. Environ Toxicol Chem 28:25222527

Forster M, V Laabs, M Lamshöft, J Groeneweg, S Zühlke, M Spiteller, M Krauss, M Kaupenjohann, W Amelung (2009). Sequestration of manure-applied sulfadiazine residues in soils. Environ Sci Technol 43:1824-1830

Francino MP (2016). Antibiotics and the Human Gut Microbiome: Dysbioses and accumulation of resistances. Front Microbiol 6; Article 1543

Franz E, J Schijven, AMDR Husman, H Blaak (2014). Meta-regression analysis of commensal and pathogenic Escherichia coli survival in soil and water. Environ Sci Technol 48:6763-6771

Gan S, EV Lau, HK Ng (2009). Remediation of soils contaminated with polycyclic aromatic hydrocarbons (PAHs). J Haz Mater 172:532-549

Grossberger A, Y Hadar, T Borch, B Chefetz (2014). Biodegradability of pharmaceutical compounds in agricultural soils irrigated with treated wastewater. Environ Pollut 185:168-177

Gulkowska A, M Sander, J Hollender, M Krauss (2013). Covalent binding of sulfamethazine to natural and synthetic humic acids: Assessing laccase catalysis and covalent bond stability. Environ Sci Technol 47:6916-6924

Gurmessa B, EF Pedretti, S Cocco, V Cardelli, G Corti (2020). Manure anaerobic digestion effects and the role of pre- and post-treatments on veterinary antibiotics and antibiotic resistance genes removal efficiency. Sci Total Environ 721:137532

Hamscher G, S Sczesny, H Höper, H Nau (2002). Determination of persistent tetracycline residues in soil fertilized with liquid manure by high-performance liquid chromatography with electrospray ionization tandem mass spectrometry. Anal Chem 74:1509-1518

He Y, Q Yuan, J Mathieu, L Stadler, N Senehi, R Sun, PJJ Alvarez (2020). Antibiotic resistance genes from livestock waste: Occurrence, dissemination, and treatment. NPJ Clean Water 3; Article 4

Hillis, DG, J Fletcher, KR Solomon, PK Sibley (2011). Effects of ten antibiotics on seed germination and root elongation in three plant species. Arch Environ Contam Toxicol 60:220-232

Ho YB, MP Zakaria, PA Latif, N Saari (2013). Degradation of veterinary antibiotics and hormone during broiler manure composting. Bioresour Technol 131:476-484

Homem V, L Santos (2011). Degradation and removal methods of antibiotics from aqueous matrices - A review. J Environ Manage 92:2304-2347

Hu X, Q Zhou, Y Luo (2010). Occurrence and source analysis of typical veterinary antibiotics in manure, soil, vegetables and groundwater from organic vegetable bases, northern China. Environ Pollut 158:2992-2998

Jechalke S, H Heuer, J Siemens, W Amelung, K Smalla (2014). Fate and effects of veterinary antibiotics in soil. Trends Microbiol 22:536-545

Jia Y, SK Khanal, H Shu, H Zhang, G-H Chen, H Lu (2018). Ciprofloxacin degradation in anaerobic sulfate-reducing bacteria (SRB) sludge system: Mechanism and pathways. Water Res 136:64-74

Kay P, PA Blackwell, ABA Boxall (2005). Transport of veterinary antibiotics in overland flow following the application of slurry to arable land. Chemosphere 59:951-959

Kim H, YS Hwang, VK Sharma (2014). Adsorption of antibiotics and iopromide onto single-walled and multi-walled carbon nanotubes. Chem Eng J 255:23-27

Kim KR, G Owens, SI Kwon, KH So, DB Lee, YS Ok (2010a). Occurrence and environmental fate of veterinary antibiotics in the terrestrial environment. Water Air Soil Pollut 214:163-174

Kim SH, HK Shon, HH Ngo (2010b). Adsorption characteristics of antibiotics trimethoprim on powdered and granular activated carbon. J Ind Eng Chem 16:344-349
Kim KR, G Owens, YS Ok, WK Park, DB Lee, SI Kwon (2012). Decline in extractable antibiotics in manure-based composts during composting. Waste Manage 32:110-116

Knapp CW, SM McCluskey, BK Singh, CD Campbell, G Hudson, DW Graham (2011). Antibiotic resistance gene abundances correlate with metal and geochemical conditions in archived Scottish soils. PLoS One 6; Article e27300

Kulshrestha P, RF Giese, DS Aga (2004). Investigating the molecular interactions of oxytetracycline in clay and organic matter: Insights on factors affecting its mobility in soil. Environ Sci Technol 38:4097-4105

Kumar K, SC Gupta, SK Baidoo, Y Chander, CJ Rosen (2005). Antibiotic uptake by plants from soil fertilized with animal manure. J Environ Qual 34:2082-2085

Kuppusamy S, D Kakarla, K Venkateswarlu, M Megharaj, YE Yoon, YB Lee (2018). Veterinary antibiotics (VAs) contamination as a global agro-ecological issue: A critical view. Agric Ecosyst Environ 257:47-59

Kurwadkar ST, CD Adams, MT Meyer, DW Kolpin (2011). Comparative mobility of sulfonamides and bromide tracer in three soils. J Environ Manage 92:1874-1881

Lehto T, JJ Zwiazek (2010). Ectomycorrhizas and water relations of trees: A review. Mycorrhiza 21:71-90

Li B, T Zhang (2010). Biodegradation and adsorption of antibiotics in the activated sludge process. Environ Sci Technol 44:3468-3473

Li B, Z Zhang, Y Ma, Y Li, C Zhu, H Li (2019). Electrokinetic remediation of antibiotic-polluted soil with different concentrations of tetracyclines. Environ Sci Pollut Res 26:8212-8225

Li H, Z Zhang, J Duan, N Li, B Li, T Song, MF Sardar, X Lv, C Zhu (2020). Electrochemical disinfection of secondary effluent from a wastewater treatment plant: Removal efficiency of ARGs and variation of antibiotic resistance in surviving bacteria. Chem Eng $J$ 392:123674

Lofrano G, R Pedrazzani, G Libralato, M Carotenuto (2017). Advanced oxidation processes for antibiotics removal: A review. Curr $\mathrm{Org}$ Chem 21:1054-1067

Luby EM, TB Moorman, ML Soupir (2016). Fate and transport of tylosinresistant bacteria and macrolide resistance genes in artificially drained agricultural fields receiving swine manure. Sci Total Environ 550:1126-1133

Macias-Corral M, Z Samani, A Hanson, G Smith, P Funk, H Yu, J Longworth (2008). Anaerobic digestion of municipal solid waste and agricultural waste and the effect of co-digestion with dairy cow manure. Bioresour Technol 99:8288-8293

Méndez-Díaz JD, GP Joya, JR Utrilla, RL Ramos, MS Polo, MAF García, NA Medellín-Castillo (2010). Kinetic study of the adsorption of nitroimidazole antibiotics on activated carbons in aqueous phase. J Colloid Interface Sci 345:481-490

Minden V, A Deloy, AM Volkert, SD Leonhardt, G Pufal (2017). Antibiotics impact plant traits, even at small concentrations. $A o B$ Plants 1; Article plx010

Mitchell SM, JL Ullman, AL Teel, RJ Watts, C Frear (2013). The effects of the antibiotics ampicillin, florfenicol, sulfamethazine, and tylosin on biogas production and their degradation efficiency during anaerobic digestion. Bioresour Technol 149:244-252

Nakonechny M, K Ikehata, M Gamal El-Din (2008). Kinetics of estrone ozone/hydrogen peroxide advanced oxidation treatment $\mathrm{Ozone}: \mathrm{Sci}$ Eng 30:249-255

National Academies of Sciences, Engineers and Medicine (2018). Science Breakthroughs to Advance Food and Agricultural Research by 2030. National Academies Press Washington DC, USA

Ostermann A, J Siemens, G Welp, Q Xue, X Lin, X Liu, W Amelung (2013). Leaching of veterinary antibiotics in calcareous Chinese croplands. Chemosphere 91:928-934

Pan M, LM Chu (2017). Fate of antibiotics in soil and their uptake by edible crops. Sci Tot Environ 599-600:500-512

Park JY, B Huwe (2016). Effect of $\mathrm{pH}$ and soil structure on transport of sulfonamide antibiotics in agricultural soils. Environ Pollut 213:561-570 
Popova IE, RDR Josue, S Deng, JA Hattey (2017). Tetracycline resistance in semi-arid agricultural soils under long-term swine effluent application. J Environ Sci Heal Part B 52:298-305

Rahman S (2019). The under reported issue of antibiotic-resistance in foodproducing animals in Pakistan. Pak Vet J 39:323-328

Rozas O, D Contreras, MA Mondaca, M Pérez-Moya, HD Mansilla (2010). Experimental design of Fenton and Photo-Fenton reactions for the treatment of ampicillin solutions. J Haz Mater 177:1025-1030

Saleem Z, MA Hassali, B Godman, M Fatima, Z Ahmad, A Sajid, IU Rehman, MU Nadeem, Z Javaid, M Malik, A Hussain (2020). Sale of WHO AWaRe groups antibiotics without a prescription in Pakistan: A simulated client study. J Pharm Pol Pract 13; Article 26

Sara P, D Giuliana, P Michele, C Maurizio, C Luca, A Fabrizio (2013). Effect of veterinary antibiotics on biogas and bio-methane production. Intl Biodeterior Biodegrad 85:205-209

Sardar MF, C Zhu, G Bing, HR Ahmad, T Song, H Li (2021). The fate of antibiotic resistance genes in cow manure composting: Shaped by temperature-controlled composting stages. Bioresour Technol 320; Article 124403

Sardar MF, HR Ahmad, MZ Rehman, M Ozturk, V Altay (2018). Absorption of foliar-applied Lead $(\mathrm{Pb})$ in rice (Oryza sativa L.): A hydroponic experiment. Fresen Enviorn Bull 27:6634-6639

Schaffer M, N Boxberger, H Börnick, T Licha, E Worch (2012). Sorption influenced transport of ionizable pharmaceuticals onto a natural sandy aquifer sediment at different $\mathrm{pH}$. Chemosphere 87:513-520

Selaledi LA, ZM Hassan, TG Manyelo, M Mabelebele (2020). The Current status of the alternative use to antibiotics in poultry production: An African perspective. Antibiotics 9:594-611

Selvam A, Z Zhao, JWC Wong (2012). Composting of swine manure spiked with sulfadiazine, chlortetracycline and ciprofloxacin. Bioresour Technol 126:412-417

Shi H, J Ni, T Zheng, X Wang, C Wu, Q Wang (2020). Remediation of wastewater contaminated by antibiotics. A review. Environ Chem Lett 18:345-360

Singh BK, P Trivedi (2017). Microbiome and the future for food and nutrient security. Microb Biotechnol 10:50-53

Song T, C Zhu, S Xue, B Li, J Ye, B Geng, L Li, MF Sardar, N Li, S Feng, $\mathrm{H} \mathrm{Li}$ (2020). Comparative effects of different antibiotics on antibiotic resistance during swine manure composting. Bioresour Technol 315; Article 123820

Stone JJ, SA Clay, Z Zhu, KL Wong, LR Porath, GM Spellman (2009) Effect of antimicrobial compounds tylosin and chlortetracycline during batch anaerobic swine manure digestion. Water Res 43:4740-4750

Stoob K, HP Singer, SR Mueller, RP Schwarzenbach, CH Stamm (2007). Dissipation and transport of veterinary sulfonamide antibiotics after manure application to grassland in a small catchment. Environ Sci Technol 41:7349-7355

Strauss C, T Harter, M Radke (2011). Effects of $\mathrm{pH}$ and manure on transport of sulfonamide antibiotics in soil. J Environ Qual 40:1652-1660

Sui Q, X Meng, R Wang, J Zhang, D Yu, M Chen, Y Wang, Y Wei (2018). Effects of endogenous inhibitors on the evolution of antibiotic resistance genes during high solid anaerobic digestion of swine manure. Bioresour Technol 270:328-336

Tasho RP, JY Cho (2016). Veterinary antibiotics in animal waste, its distribution in soil and uptake by plants: A review. Sci Tot Environ 563-564:366-376
Thiele-Brun S, DPeters (2007). Photodegradation of pharmaceutical antibiotics on slurry and soil surfaces. Landbauforsch. Volkenrode 57:13-23

Thiele-Bruhn S, T Seibicke, H-R Schulten, P Leinweber (2004). Sorption of sulfonamide pharmaceutical antibiotics on whole soils and particlesize fractions. J Environ Qual 33:1331-1343

USDA (2009). Natural Resources Conservation Service. Agricultural Waste Management Field Handbook, Washington DC, USA

Vasudevan D, GL Bruland, BS Torrance, VG Upchurch, AA MacKay (2009). pH-dependent ciprofloxacin sorption to soils: Interaction mechanisms and soil factors influencing sorption. Geoderma 151:68-76

Wegst-Uhrich SR, DAG Navarro, L Zimmerman, DS Aga (2014). Assessing antibiotic sorption in soil: A literature review and new case studies on sulfonamides and macrolides. Chem Cent J 8; Article 5

Wei R, F Ge, S Huang, M Chen, R Wang (2011). Occurrence of veterinary antibiotics in animal wastewater and surface water around farms in Jiangsu Province, China. Chemosphere 82:1408-1414

Wu N, W Zhang, S Xie, M Zeng, H Liu, J Yang, X Liu, F Yang (2019). Increasing prevalence of antibiotic resistance genes in manured agricultural soils in northern China. Front Environ Sci Eng 1; Article 14

Wu Q, Z Li, H Hong, R Li, WT Jiang (2013). Desorption of ciprofloxacin from clay mineral surfaces. Water Res 47:259-268

Xue G, M Jiang, H Chen, M Sun, Y Liu, X Li, P Gao (2019). Critical review of ARGs reduction behavior in various sludge and sewage treatment processes in wastewater treatment plants. Crit Rev Environ Sci Technol 49:1623-1674

Yang Q, S Ren, T Niu, Y Guo, S Qi, X Han, D Liu, F Pan (2013). Distribution of antibiotic-resistant bacteria in chicken manure and manure-fertilized vegetables. Environ Sci Pollut Res 21:1231-1241

Yu F, Y Li, S Han, J Ma (2016). Adsorptive removal of antibiotics from aqueous solution using carbon materials. Chemosphere 153:365-385

Zarfl C, J Klasmeier, M Matthies (2009). A conceptual model describing the fate of sulfadiazine and its metabolites observed in manureamended soils. Chemosphere 77:720-726

Zhang M, LY He, YS Liu, JL Zhao, JN Zhang, J Chen, QQ Zhang, GG Ying (2020). Variation of antibiotic resistome during commercial livestock manure composting. Environ Intl 136:1-12

Zhang X, R Li (2018). Variation of antibiotics in sludge pretreatment and anaerobic digestion processes: Degradation and solid-liquid distribution. Bioresour Technol 255:266-272

Zhang XX, JS Gao, YH Cao, XT Ma, JZ He (2013). Long-term rice and green manure rotation alters the endophytic bacterial communities of the rice root. Microb Ecol 66:917-926

Zhang Z, B Li, N Li, MF Sardar, T Song, C Zhu, X Lv, H Li (2019). Effects of UV disinfection on phenotypes and genotypes of antibioticresistant bacteria in secondary effluent from a municipal wastewater treatment plant. Water Res 157:546-554

Zhu N, H Jin, X Ye, W Liu, D Li, GM Shah, Y Zhu (2020). Fate and driving factors of antibiotic resistance genes in an integrated swine wastewater treatment system: From wastewater to soil. Sci Total Environ 721; Article 137654

Zhu YG, Y Zhao, B Li, CL Huang, SY Zhang, S Yu, YS Chen, T Zhang, MR Gillings, JQ Su (2017). Continental-scale pollution of estuaries with antibiotic resistance genes. Nat Microbiol 2:16270 